\title{
PENCERMINAN PADA DIMENSI TIGA
}

\author{
Anggit Dwi Kuncoro ${ }^{1}$, Ikrar Pramudya ${ }^{2}$ \\ ${ }^{1,2}$ Universitas Sebelas Maret
}

\begin{abstract}
The concept of reflection in three-dimensional is almost the same as the concept of reflection in the two-dimensional. However, the mirror in three-dimensional is in the form of flat plane. Reflection in three-dimensional is a function that maps each point in such a way to meet the following requirements: distance between the prapeta point and the mirror is the distance between the mirror to the mapping result, the line connecting prapeta point with the mapping must be perpendicular to the mirror, and the structure and its reflection must be congruent. To get the reflection function, it can be carried out analytically. First, take flat plane as a mirror and the point that will be reflected in three-dimensional. A straight line is made through that point and it is perpendicular to the mirror, so the breakpoint can be determined. By utilizing shifts in three-dimensional, translucent point can be shifted in line with vector $\overrightarrow{\boldsymbol{a}}=\overrightarrow{\boldsymbol{a}_{\boldsymbol{t}}}-$ $\overrightarrow{\boldsymbol{a}_{0}}$ where $\boldsymbol{a}_{\boldsymbol{t}}$ is the point and $\boldsymbol{a}_{\mathbf{0}}$ is the starting point. So, the point as the result of mirroring can be obtained. The results of this study reveal that: mirroring in threedimensional is a transformation because its function is a bijective. Reflection is involution which means that the results of twice multiplications are identity. Mirroring is not commutative. The result of twice parallel reflection composition can be called as reflection. The result of $\mathrm{n}$ multiplication of mirroring composition parallel to the coordinate and there is a distance is called as reflection.
\end{abstract}

Keywords:Involution, Composition, Transformation.

\section{PENDAHULUAN}

Geometri merupakan salah satu cabang ilmu matematika yang sangat terkait dengan bentuk, ukuran, dan pemposisian. Geometri adalah studi hubungan ruang. Geometri transformasi adalah bagian dari geometri yang membicarakan perubahan, baik perubahan letak maupun bentuk. Geometri transformasi lebih sering disebut transformasi adalah mengubah setiap koordinat titik (titik-titik dari suatu bangun) menjadi koordinat lainnya pada bidang dengan satu aturan tertentu.

Materi geometri transformasi baik di SMA maupun di perguruan tinggi dibatasi hanya pada bidang datar (dimensi dua). Pada dasarnya konsep transformasi pada bidang datar (dimensi dua) hampir sama dengan transformasi pada ruang (dimensi tiga). Perbedaanya terletak pada cerminnya, cermin pada dimensi dua berupa suatu garis lurus sedangkan cermin pada dimensi tiga berupa bidang datar.

Dalam buku Geometric Modeling edisi kedua yang dikarang oleh Michael E. Mortenson membahas geometri transformasi pada ruang atau dimensi tiga. Hanya saja pembahasanya masih terbatas, yaitu pencerminan terhadap bidang-bidang koordinat. Pada buku tersebut belum dijelaskan sifat-sifat pencerminan seperti pada refleksi pada dimensi dua.

Berdasarkan latar belakang yang telah diuraikan, maka dapat dirumuskan masalahan penelitian sebagai berikut: (1) Bagaimana formula pencerminan terhadap 
sebarang cermin pada dimensi tiga?, (2) Bagaimana sifat-sifat pencerminan pada dimensi tiga?, dan (3) Bagaimana komposisi pencerminan pada dimensi tiga?. Tujuan penelitian ini adalah : (1) Menemukan formula pencerminan terhadap sebarang cermin pada dimensi tiga, (2) Mendeskripsikan sifat-sifat refleksi pada dimensi tiga, dan (3) Mendeskripsikan sifat-sifat komposisi pencerminan pada dimensi tiga. Hasil penelitian ini diharapkan dapat memberikan manfaat yaitu : (1) Memberikan informasi atau gambaran bagi pembaca mengenai pencerminan pada dimensi tiga, dan (2) memberikan sumbangan penelitian pada bidang matematika, khususnya geometri.

\section{METODE PENELITIAN}

Materi pokok yang menjadi bahan dasar penelitian ini adalah karya tulis ilmiah hasil penelitian para pakar yang telah dimuat dalam buku atau jurnal baik yang termuat di media cetak maupun media elektronik. Adapun, metode penelitian yang digunakan adalah kajian pustaka/studi literatur. Caranya adalah dengan melakukan kajian secara luas dan mendalam terhadap sumber-sumber referensi yang relevan dengan topik penelitian atau permasalahan penelitian. Selanjutnya, berdasarkan prinsip-prinsip penarikan simpulan yang sesuai dengan kaidah silogisma matematika, diiringi dengan menerapkan definisi/pengertian dan sifat/teorema (bila diperlukan), kemudian ditarik serangkaian simpulan antara, dan akhirnya dapat ditarik simpulan yang sekaligus merupakan jawaban dari masalah penelitian. Pada umumnya, hasil penelitian disajikan dalam bentuk definisi/pengertian, lema, akibat, sifat/teorema, atau masalah yang terselesaikan.

\section{HASIL DAN PEMBAHASAN}

Pencerminan terhadap bidang $\mathrm{V}$, yang dinyatakan $\mathrm{M}_{\mathrm{V}}$ adalah relasi yang memenuhi

1. $\mathrm{M}_{\mathrm{V}}(\mathrm{A})=\mathrm{A}$, untuk $\mathrm{A}$ di $\mathrm{V}$

2. $\mathrm{M}_{\mathrm{V}}(\mathrm{B})=\mathrm{B}^{\prime}$, untuk $\mathrm{B}$ di luar $\mathrm{V}$ sedemikian sehingga $\mathrm{BB}^{\prime} \perp \mathrm{V}$ dan $\mathrm{d}(\mathrm{B}, \mathrm{V})=\mathrm{d}\left(\mathrm{B}^{\prime}, \mathrm{V}\right)$

\section{A. Fungsi Analitik Pencerminan}

Pencerminan terhadap bidang $\mathrm{V}: \mathrm{ax}+\mathrm{by}+\mathrm{cz}+\mathrm{d}=0 \mathrm{a}, \mathrm{b}, \mathrm{c}, \mathrm{d} \in \mathrm{R} ;(\mathrm{a}, \mathrm{b}, \mathrm{c}, \mathrm{d}) \neq(0,0,0, \mathrm{~d}), \mathrm{d} \neq 0$ yang memenuhi definisi pencerminan pada dimensi tiga sebagai berikut : 


$$
M_{V}\left(\begin{array}{l}
x \\
y
\end{array}\right)=\left(\begin{array}{c}
x-\frac{2 a(a x+b y+c z+d)}{\left(a^{2}+b^{2}+c^{2}\right)} \\
y-\frac{2 b(a x+b y+c z+d)}{\left(a^{2}+b^{2}+c^{2}\right)} \\
z-\frac{2 c(a x+b y+c z+d)}{\left(a^{2}+b^{2}+c^{2}\right)}
\end{array}\right)
$$

Bila cerminnya $\mathrm{V}_{1}: \mathrm{x}=\mathrm{k}_{1}, \mathrm{~V}_{2}: \mathrm{y}=\mathrm{k}_{2}$, dan $\mathrm{V}_{1}: \mathrm{z}=\mathrm{k}_{3}$ dimana $\mathrm{k}_{1}, \mathrm{k}_{2}, \mathrm{k}_{3} \in \mathrm{R}$, maka

$$
\begin{aligned}
& M_{V_{1}}\left(\begin{array}{l}
x \\
y \\
z
\end{array}\right)=\left(\begin{array}{c}
-x+2 k_{1} \\
y \\
z
\end{array}\right) \\
& M_{V_{2}}\left(\begin{array}{l}
x \\
y \\
z
\end{array}\right)=\left(\begin{array}{c}
x \\
-y+2 k_{2} \\
z
\end{array}\right) \\
& M_{V_{3}}\left(\begin{array}{l}
x \\
y \\
z
\end{array}\right)=\left(\begin{array}{c}
x \\
y \\
-z+2 k_{3}
\end{array}\right) .
\end{aligned}
$$

B. Pencerminan adalah Transformasi

M fungsi analitik pencerminan pada dimensi tiga merupakan suatu transformasi karena memenuhi :
i. $\quad \forall \mathrm{A}, \mathrm{B} \in \mathrm{R}^{3} ; \mathrm{A}=\mathrm{B} \rightarrow \mathrm{M}(\mathrm{A})=\mathrm{M}(\mathrm{B})$
ii. $\quad \forall A \in R^{3} \exists B \in R^{3} \exists A=M(B)$
iii. $\quad \forall \mathrm{A}, \mathrm{B} \in \mathrm{R}^{3} ; \mathrm{M}(\mathrm{A})=\mathrm{M}(\mathrm{B}) \rightarrow \mathrm{A}=\mathrm{B}$

C. Pencerminan Bersifat Involusi

Transformasi pencerminan adalah involusi.

Artinya,

$$
\begin{gathered}
\mathrm{M}_{\mathrm{v}} \mathrm{M}_{\mathrm{v}}=\mathrm{M}_{\mathrm{v}^{2}}=\mathrm{I} \\
\mathrm{M}(\mathrm{M}(\mathrm{A}))=\mathrm{A}, \forall A \in \mathrm{R}^{3}
\end{gathered}
$$

D. Pencerminan tidak Bersifat komutatif

$$
\forall M_{1}, M_{2} \in \mathcal{M}=\left\{M: R^{3} \rightarrow R^{3} \mid M \text { pencerminan }\right\}
$$

$$
\mathcal{M} \text { komutatif } \Leftrightarrow \forall M_{1}, M_{2} \in \mathcal{M} \ni M_{1} \circ M_{2}=M_{2} \circ M_{1} \text {. }
$$

Pilih bidang datar $V_{1}: x=0, V_{1}: x+y+1=0, A=(0,0,0)$

$$
M_{V_{2}}\left(M_{V_{1}}\left(\begin{array}{l}
0 \\
0 \\
0
\end{array}\right)\right)=\left(\begin{array}{c}
-2 \\
-2 \\
0
\end{array}\right)
$$




$$
M_{V_{1}}\left(M_{V_{2}}\left(\begin{array}{l}
0 \\
0 \\
0
\end{array}\right)\right)=\left(\begin{array}{c}
2 \\
-2 \\
0
\end{array}\right)
$$

$\exists M_{1}, M_{2} \in \mathcal{M} \ni M_{1} \circ M_{2} \neq M_{2} \circ M_{1} \rightarrow \mathcal{M}$ tidak komutatif.

Penceminan tidak bersifat komutatif.

E. Komposisi Dua Pencerminan Sejajar

"Hasil kali dua pencerminan yang sejajar adalah suatu pencerminan."

Misal

$$
\begin{aligned}
& V_{1}: a x+b y+c z+d_{1}=0 \\
& V_{2}: a x+b y+c z+d_{2}=0 \\
& \left(a, b, c, d_{1}, d_{2}\right) \neq\left(0,0,0, d_{1}, d_{2}\right) \text { dengan } d_{1} \neq 0 \text { dan } d_{2} \neq 0, d_{1} \neq d_{2} \\
& M_{V_{2}}\left(M_{V_{1}}\left(\begin{array}{l}
x \\
y \\
z
\end{array}\right)\right)=M_{V}\left(\begin{array}{l}
x \\
y \\
z
\end{array}\right) \rightarrow V_{1}\left\|V_{2}\right\| V \\
& M_{V_{2}}\left(M_{V_{1}}\left(\begin{array}{l}
x \\
y \\
Z
\end{array}\right)\right)=\left(\begin{array}{c}
x-\frac{2 a\left(2 a x+2 b y+2 c z+3 d_{1}-d_{2}\right)}{R} \\
y-\frac{2 b\left(2 a x+2 b y+2 c z+3 d_{1}-d_{2}\right)}{R} \\
z-\frac{2 c\left(2 a x+2 b y+2 c z+3 d_{1}-d_{2}\right)}{R}
\end{array}\right)=M_{V}\left(\begin{array}{l}
x \\
y \\
Z
\end{array}\right)
\end{aligned}
$$

Dengan

$V: 2 a x+2 b y+2 c z+3 d_{1}-d_{2}=0$ atau

$V: a x+b y+c z+\frac{3 d_{1}-d_{2}}{2}=0$

Jelas bahwa $\mathrm{V}_{1}\left\|\mathrm{~V}_{2}\right\| \mathrm{V}$

F. Komposisi n Pencerminan Sejajar Bidang Koordinat Berjarak Tetap

Diberikan bidang (cermin) yang sejajar dengan bidang XOZ

$$
V_{n}: y=a+(n-1) b, n \in \mathbb{N}
$$

Formula dari hasil $\mathrm{n}$ kali pencerminan dari $V_{1}$ dilanjut pencerminan $V_{2}$ dilanjut pencerminan dari $V_{3}$ sampai dengan pencerminan dari $V_{n}$

$$
M_{V_{n}}\left(M_{V_{(n-1)}} \cdots\left(M_{V_{4}}\left(M_{V_{3}}\left(M_{V_{2}}\left(M_{V_{1}}(A)\right)\right)\right)\right)\right)=\left(\begin{array}{c}
x \\
y_{n} \\
z
\end{array}\right)
$$

Untuk n ganjil, $y_{n}=-y+2 a+(n-1) b$

Untuk n genap, $y_{n}=y+n b$.

komposisi $\mathrm{n}$ kali pencerminan terhadap bidang-bidang yang sejajar deng bidang YOZ. 
Misalkan bidang-bidang tersebut adalah

$$
\begin{gathered}
V_{n}: x=a+(n-1) b, n \in \mathbb{N} \\
M_{V_{n}}\left(M_{V_{(n-1)}} \ldots\left(M_{V_{4}}\left(M_{V_{3}}\left(M_{V_{2}}\left(M_{V_{1}}\left(\begin{array}{l}
x \\
y \\
z
\end{array}\right)\right)\right)\right)\right)=\left(\begin{array}{c}
x_{n} \\
y \\
Z
\end{array}\right)\right)
\end{gathered}
$$

berlaku untuk setiap $\mathrm{n}$ bilangan asli.

Untuk n ganjil, $x_{n}=-x+2 a+(n-1) b$.

Untuk n genap, $x_{n}=x+n b$.

Komposisi untuk bidang-bidang yang sejajar dengan XOY

Misalkan bidang-bidang tersebut adalah

$$
\begin{gathered}
V_{n}: z=a+(n-1) b, n \in \mathbb{N} \\
M_{V_{n}}\left(M_{V_{(n-1)}} \ldots\left(M_{V_{4}}\left(M_{V_{3}}\left(M_{V_{2}}\left(M_{V_{1}}\left(\begin{array}{l}
x \\
y \\
z
\end{array}\right)\right)\right)\right)\right)=\left(\begin{array}{c}
x \\
y \\
z_{n}
\end{array}\right)\right)
\end{gathered}
$$

berlaku untuk setiap $\mathrm{n}$ bilangan asli.

Untuk n ganjil, $z_{n}=-z+2 a+(n-1) b$.

Untuk n genap, $z_{n}=z+n b$.

\section{SIMPULAN DAN SARAN}

Suatu relasi yang memenuhi definsi pencerminan dimensi tiga sebagai berikut:Pencerminan terhadap bidang $V: a x+b y+c z+d=0$

$$
M_{V}\left(\begin{array}{l}
x \\
y \\
z
\end{array}\right)=\left(\begin{array}{c}
x-\frac{2 a(a x+b y+c z+d)}{\left(a^{2}+b^{2}+c^{2}\right)} \\
y-\frac{2 b(a x+b y+c z+d)}{\left(a^{2}+b^{2}+c^{2}\right)} \\
z-\frac{2 c(a x+b y+c z+d)}{\left(a^{2}+b^{2}+c^{2}\right)}
\end{array}\right)
$$

Sifat-sifat pencerminan pada dimensi tiga dapat disimpulkan adalah sebagai berikut : (1) Pencerminan merupakan transformasi, karena $M_{V}$ adalah fungsi bijektif dari $R^{3}$ ke $R^{3}$,(2) Transformasi pencerminan bersifat involusi, artinya invers dari setiap pencerminan bidang adalah pencerminan bidang itu sendiri., (3) Pencerminan tidak bersifat komutatif, (4) Komposisi dua pencerminan yang sejajar adalah suatu pencerminan. (5) Komposisi $n$ pencerminan sejajar bidang-bidang koordinat berjarak sama adalah suatu pencerminan. 
Dalam makalah ini dibahas fungsi analitik pencerminan pada dimensi tiga, pencerminan bersifat involusi, pencerminan tidak bersifat komutatif, komposisi dua pencerminan yang sejajar, dan komposisi $\mathrm{n}$ kali pencerminan yang sejajar dengan bidangbidang koordinat dan berjarak tetap. Bagi pembaca yang tertarik dengan materi pencerminan pada dimensi tiga, bisa mengembangkan untuk komposisi dua cermin yang membentuk suatu sudut, dan komposisi n kali cermin sebarang dengan jarak tetap.

\section{DAFTAR PUSTAKA}

Mortenson, M. E. (1996). Geometric Modeling. New York: John Wiley \& Sons, lnc.

Siswanto, \& Wibowo, S. (2007). Buku Tutorial untuk Mata Kuliah Geometri 1. Surakarta: Matematika FMIPA UNS.

Suyono. (2008). Geometri Analitik Ruang. Surakarta: Sebelas Maret University Press. 